\title{
Nitrogen uptake capacities of maize and sorghum crops in different nitrogen and water supply conditions
}

\author{
G Lemaire ${ }^{1 *}, X$ Charrier $^{2}, Y$ Hébert ${ }^{2}$ \\ 1 Station d'écophysiologie des plantes fourragères; \\ 2 Station d'amélioration des plantes fourragères, Inra, F-86600 Lusignan
}

(Received 13 October 1995; accepted 16 April 1996)

\begin{abstract}
Summary - The dynamics of dry-matter accumulation and nitrogen uptake of sorghum and maize crops were compared over two successive years under dry and irrigated conditions. In non-limiting situations for growth, with irrigation and high nitrogen fertilization, maize growth was higher than that of sorghum because the leaf area index of maize developed earlier, leading to a larger quantity of intercepted radiation. The efficiency of transforming intercepted energy into aerial biomass varied little between the two species. In situations where nitrogen was limiting, the capacity of sorghum crops to take up nitrogen from the soil was always higher than that of maize. This feature was not linked to the greater planting density of the sorghum crop ( $50 \mathrm{~cm}$ between the rows) compared with the maize crop $(75 \mathrm{~cm})$, but seemed to be a characteristic of the species. A careful study of the evolution of the nitrogen nutrition level of the different crops throughout their growth showed that sorghum was capable of taking up much larger quantities of nitrogen from the soil than maize before its nitrogen nutrition became limiting. Drought reduced nitrogen availability in the soil for both crops. Maize was more sensitive to this restriction in nitrogen nutrition, and in addition to the direct effect of a water deficit on dry-matter accumulation in maize there was also this indirect effect of a nitrogen-nutrition deficit. All the results obtained in this series of experiments showed that the potential production of sorghum was lower than that of maize, but that its adaptation to limiting growth conditions, drought and limited nitrogen input should enable this species to grow in extensive cropping conditions. Moreover, the higher $\mathbf{N}$ uptake/water consumption of sorghum compared to maize indicates that the risk of nitrate leaching in the winter following a sorghum crop should be lower than after maize.
\end{abstract}

nitrogen uptake capacity / nitrogen nutrition index / water-nitrogen interaction

Résumé - Capacités de prélèvement d'azote de cultures de maïs et de sorgho dans différentes conditions d'alimentation hydrique. Durant 2 années successives, les dynamiques de croissance en matière sèche et de prélèvement d'azote de cultures de sorgho et de maïs ont été comparées en conditions sèches et irriguées. En situations non limitantes pour la croissance, irrigation et fertilisation élevée en azote, la croissance du maïs est supérieure à celle du sorgho du fait d'une mise en place plus précoce de lindice foliaire de la culture conduisant à une plus grande quantité de rayonnement intercepté. Les efficiences de transformation de l'énergie interceptée en biomasse aérienne restent peu différentes entre les deux espèces. En situations d'apport limité en azote, les capacités de prélèvement de l'azote du sol par les cultures de sorgho ont toujours été supérieures à celles du maïs. Cette propriété n'est pas liée à la densité de plantation plus importante de la culture du sorgho (50 cm entre les rangs) par rapport à celle du maïs $(75 \mathrm{~cm})$, mais semble bien une caractéristique de l'espèce. La détermination de l'évolution du

* Correspondence and reprints 
niveau de nutrition azotée des différentes cultures au cours de leur croissance a permis de montrer que le sorgho était capable d'extraire des quantités d'azote du sol bien supérieures à celles du maïs avant de voir sa nutrition azotée devenir limitante. La sécheresse diminue la disponibilité en azote du sol pour les deux cultures. Le maïs est plus sensible à cette restriction de nutrition azotée, et, à l'effet direct du déficit hydrique sur la croissance en matière sèche de cette espèce, s'ajoute un effet indirect de déficit de nutrition azotée. L'ensemble des résultats obtenus dans cette série d'expérimentations montre que la production potentielle du sorgho est plus faible que celle du maïs, mais que son adaptation à des conditions limitantes de croissance, sécheresse et apports limités d'azote doit permettre à cette espèce de se développer dans des conditions de culture extensive. De plus, le rapport plus élevé pour le sorgho que pour le maïs entre le prélèvement d'azote et la consommation d'eau indique que les risques de lessivage de nitrate doivent être réduits après une culture de sorgho en comparaison avec le maïs.

capacité de prélèvement d'azote / index de nutrition azotée / interaction eau-azote

\section{INTRODUCTION}

Present constraints in agricultural production are aimed at reducing the production costs of different crops and limiting the negative effects on the environment brought about by intensive cultivation practices. Research is concentrating more on adapting crops to the limiting conditions of the environment rather than on increasing the genetic potential of plants which requires increased use of inputs which are costly and potentially polluting. Water supply and nitrogen nutrition of crops represent the two essential factors for agricultural productivity on which farmers can act directly in the short term. In a region subjected to major summer droughts, like the central west of France, maize production is hardly conceivable today without recourse to irrigation. Managing a crop under irrigation requires considerable nitrogen fertilization in order for it to reach or approach the potential production of the genotype used and thus be economically viable. However, in this same region, sorghum, which can be grown without irrigation, can be considered as a less intensive alternative to maize cultivation. The aim of this work was to compare the nitrogen uptake dynamics of the two species in various cultivation conditions in order to verify the interest which sorghum cultivation might represent in production systems limiting nitrogen input with a view to reducing the risks of pollution.

The production potential of a crop, namely what is obtained in the absence of any limiting factor other than non-modifiable climatic factors (radiation and temperature), is determined by its capacity to intercept incident solar radiation and by its capacity to convert this energy into aerial biomass (Monteith, 1977; Biscoe and Gallagher, 1977; Gosse et al, 1986). This approach to crop growth makes it possible to analyse the differences between species and varieties; it also makes it possible to analyse the effects of limiting factors such as water or nitrogen deficits. These effects can then be quantified in the form of deviations to the potential relative value. This method therefore makes it possible to compare the reaction and the sensitivity of the different crops at varying degrees of environmental stress. This requires a consistent and sufficiently general method for estimating the level of stress undergone by the crop.

The level of nitrogen nutrition deficit of a crop can be estimated using the nitrogen nutrition index (NNI) developed by Lemaire et al (1989). This model is based on the existence of a stable relationship between the optimum nitrogen concentration of a crop and its biomass (Lemaire and Salette, 1984). Greenwood et al (1990) have shown that the optimum plant N\% decreased unmistakably according to the increase in crop biomass. This curve in the evolution of the critical $\mathrm{N}$ content is identical for all the species of the same metabolic group (C3 or C4). For $\mathrm{C} 4$ species, Lemaire and Chartier (1992) have proposed a single curve from data including maize and sorghum crops in tropical and temperate environments:

$$
\mathrm{N} \%=3.6(\mathrm{DM})^{-0.34}
$$

However this equation has been established with a data base including some points which could be in either sub-optimal or in supra-optimal $\mathrm{N}$ conditions. More recent data obtained by Plenet (1995) on maize in a temperate zone allow a more precise determination of the decline of the critical plant $\mathrm{N} \%$ with increasing crop mass:

$$
\mathrm{N} \%=3.4(\mathrm{DM})^{-0.37}
$$

For this work, we prefered to use equation [2] as reference of the critical plant N\% for the two species. 
According to Lemaire et al (1989), the level of a crop nitrogen nutrition can be estimated by the ratio between the actual nitrogen content of this crop $\left(N_{\text {act }}\right)$ and the optimum nitrogen content $\left(N_{\text {opt }}\right)$ calculated using equation [2] for a DM value corresponding to the crop biomass. This $N_{\text {act }} / N_{\text {opt }}$ ratio may be higher than 1 in situations of excess nitrogen uptake by the crop, and lower than 1 as the lack of nitrogen limits the growth of the crop.

Equation [2] can be expressed in terms of nitrogen uptake by the crop:

$$
\mathrm{N} \mathrm{kg} / \mathrm{ha}=34(\mathrm{DM})^{0.63}
$$

This equation implies that the metabolic efficiency of nitrogen, that is the reciprocal of the quantity of nitrogen taken up per unit of biomass produced, increases with increasing crop biomass. This shows that comparisons of nitrogen efficiency between two crops are only valid if they are carried out at an equivalent biomass. However, equation [3] should show possible differences in nitrogen uptake capacities between the two crops. If such differences exist, they should be expressed by differences in the $\mathrm{NNI}$ in the same soil with limited nitrogen availability: the crop better able to take up nitrogen should maintain a higher $N_{\text {act }} / N_{\text {opt }}$ ratio. In other words, the nitrogen input required to obtain the maximum growth of this crop in a given soil would be lower.

This equation makes it possible to compare the intrinsic nitrogen uptake capacity of different crops, independently of their differences in potential growth. The nitrogen uptake capacity of a crop depends first on the size of the root system. Evaluating the uptake capacities at an equivalent level of aerial biomass therefore only makes it possible to take into account the size of the root system relative to the size of the aerial system. Of course, the spatial distribution of roots in the different soil horizons may also be determining. Comparing two crops with different row spacings ( $75 \mathrm{~cm}$ in maize and $50 \mathrm{~cm}$ in sorghum) could lead to attributing to the species differences in fact caused by planting distances. Finally, nitrogen uptake by the crop may be greatly disturbed by the water status of the different soil horizons as shown by Lemaire and Denoix (1987) on perennial grass stands. Differences in nitrogen uptake capacity between species can be caused partly by differences in water consumption in the different soil horizons.
In order to determine whether there was an intrinsic difference in nitrogen uptake capacity between maize and sorghum, we undertook a series of experiments to carry out this comparison by putting aside the differences caused by the water supply as well as those possibly caused by the planting method specific to each crop.

\section{MATERIALS AND METHODS}

Two different experiments were conducted in 1991 and 1992 on the experimental farm of the Station d'amélioration des plantes fourragères, Inra, Lusignan $\left(46.26^{\circ} \mathrm{N} ; 0.07^{\circ} \mathrm{E}\right)$.

\section{General experimental conditions}

\section{Soil}

The soil type, locally called 'terres rouges à châtaigniers' was a brown leached soil on loam, overlying a red pisolitic clay. The depth of the loam was approximately $90-100 \mathrm{~cm}$ and this was generally a horizon well-colonized by roots. The underlying red clay was penetrated by roots only in places where there were cracks and worm tunnels and contributed only minimally to the water supply of the crops. This soil had a large available water supply, of about $200 \mathrm{~mm}$ for $1 \mathrm{~m}$ depth. The organic matter content was around $3 \%$ and was maintained by periodic applications of manure. The $P$ and $K$ contents were maintained at sufficient levels by regular inputs.

\section{Climate}

1991 was characterized by a relatively cool beginning of May which impeded more particularly the leaf development of sorghum. Subsequently, July and August were exceptionally hot, with 25 days exceeding a maximum temperature of $30^{\circ} \mathrm{C}$. Rainfall amounted to only $58 \mathrm{~mm}$ over the period from 1 May to 1 September for a Penman PET of $530 \mathrm{~mm}$. The drought was therefore exceptionally severe during this period; however the rain returned in September. The water supply necessary to maintain irrigated treatments without water deficiency was $360 \mathrm{~mm}$.

1992 was characterized by more moderate temperatures at the beginning of May and there were no very high temperatures during the summer period. Total rainfall over the period from 1 May to 1 September amounted to a total of $295 \mathrm{~mm}$ for a Penman PET of $504 \mathrm{~mm}$, which led to only a relatively moderate water deficit after 15 August. Water supply by irrigation was limited to $140 \mathrm{~mm}$. 


\section{Experimental designs}

\section{Experiment 1 (1991)}

The growth and nitrogen uptake of a maize genotype (cv Furio) and a grain sorghum genotype (cv DK18) were compared at two levels of nitrogen fertilization (N1: $30 \mathrm{~kg} / \mathrm{ha}$ and N2: $200 \mathrm{~kg} / \mathrm{ha}$ ) in irrigated and nonirrigated conditions. The level of N2 fertilization was determined to be non-limiting and the $\mathrm{N} t$ level to enable the nitrogen uptake capacities of the two genotypes to be expressed in situations of low soil nitrogen availability. For practical reasons concerning irrigation, two separate experiments were conducted on adjacent plots. Each experiment was laid out on a three-block split-plot design with the different 'nitrogen' treatments in sub-blocks. The two species were planted on 15 May: maize at a density of 90000 seeds/ha with a $75-\mathrm{cm}$ row spacing and sorghum at a density of 400000 seeds/ha with a $50-\mathrm{cm}$ row spacing. Nitrogen was supplied according to each treatment in the form of ammonium nitrate after sowing. Weeds were controlled in all the experiments before sowing, using atrazine at a dose of $1.5 \mathrm{~kg} / \mathrm{ha}$.

\section{Experiment 2 (1992)}

In the second experiment, two genotypes of each species were compared: Furio and Yamba cultivars for maize and DK18 and Argence cultivars for sorghum. In order to test the possible effect of row spacing on the nitrogen uptake capacities of the crops, we planted the two genotypes Furio and DK18 with two row spacings of 50 and $75 \mathrm{~cm}$. The other two genotypes, Yamba and Argence, were planted at their normal spacings of 75 and $50 \mathrm{~cm}$ respectively. A single $50 \mathrm{~kg} / \mathrm{ha}$ dose of nitrogen was applied, which was judged to be limiting. As in 1991, two adjacent trials were set up, one in dry conditions and the other irrigated. The layout included three complete random blocks. The treatments were laid out in split-plot design, the four genotypes in subblocks and, for the two genotypes Furio and DK18, two-row spacings in sub-plots.

\section{Measuring growth and nitrogen uptake}

For both experiments, the dry matter growth of each treatment was monitored by sampling aerial biomass every week at the beginning of the cycle and every two weeks at the end of the cycle. For maize, on each subplot 12 adjacent plants were sampled on two adjacent rows, ie, 24 plants per plot. The distance between the first and last plants sampled on a row was recorded to calculate the dry matter per $\mathrm{m}^{2}$. For sorghum, given the greater density of plants along the row and their large numbers of tillers, identifying individual plants was impossible and we sampled $1.5 \mathrm{~m}$ along the two adjacent rows twice per sub-plot. In both cases the two sampled rows were weighed separately in order to estimate intra-plot variance. After weighing, the green matter harvested from the two adjacent rows was chopped up. A 1-kg sample was then taken to determine the dry matter content, after having been ovendried at $80^{\circ} \mathrm{C}$ for $48 \mathrm{~h}$. The samples were then ground and the nitrogen content was estimated in the laboratory ( $\mathrm{N} \mathrm{Kjeldahl).} \mathrm{Nitrogen} \mathrm{uptake} \mathrm{was} \mathrm{calculated} \mathrm{for}$ each of the treatments and for each sampling date from dry biomass and the corresponding nitrogen contents.

\section{Measuring the leaf area index of the crop and estimating the quantity of intercepted radiation}

During experiment 1 , only on the $\mathrm{N} 2$ nitrogen dose under irrigated conditions, the evolution of the leaf area index of the two genotypes was monitored with an LAI 2000 LICOR, which made it possible to estimate in situ the quantity of leaf area per unit of soil surface. This estimation was made every two weeks by taking ten measurements per elementary plot. Monitoring the leaf area development enabled us to estimate daily the proportion of incident photosynthetic active radiation (PAR) which is intercepted by the crop using the following equation:

$$
E_{i}=\mathrm{PAR}_{\mathrm{i}} / \mathrm{PAR}_{0}=0.95\left(1-\mathrm{e}^{-0.66 \mathrm{LAl}}\right)
$$

with $\mathrm{PAR}_{0}$ : incident radiation, $\mathrm{PAR}_{\mathrm{i}}$ : intercepted radiation, LAl: leaf area index of the crop.

The value of the coefficient 0.66 is the value determined by Varlet-Grancher et al (1989) for sorghum; it is no different from the value of 0.70 determined by Bonhomme et al (1982) for maize, or from the 0.65 used in the CERES-Maize model (Jones and Kiniry, 1986). Ruget et al (1990) have shown that in the range of $0.65-0.70$, the impact of this coefficient on the quantity of PAR intercepted by the crop was negligible, which justified retaining only a single value for the two species.

\section{Determining the nitrogen nutrition level of crops}

The NNI of the crop was determined at each sampling in accordance with the model developed by Lemaire et al (1989) on forage grasses. This index is calculated by using the optimum dilution curve corresponding to C4 plants [eq 2]. It is calculated by:

$$
\mathrm{NNI}=N_{\mathrm{acl}} / N_{\mathrm{c}}
$$

where $N_{\text {act }}$ is the actual $N$ concentration in shoots and $N_{c}$ is the critical $\mathrm{N} \%$ value corresponding to the shoot biomass. At each sampling date, the value of the NNI was calculated for each of the plots. Therefore statistical analyses were possible on this variable. 


\section{Water consumption}

Soil water content variations was monitored on each $\mathrm{N} 2$ treatment of experiment 1 by neutronic gauge measurements on each $10 \mathrm{~cm}$ of the soil from the surface layer to a depth of $170 \mathrm{~cm}$. The same measurements were made during experiment 2 for all treatments of Furio and DK18. The total water consumption was calculated from these measurements, as well as the contribution of each soil layer.

\section{Root density profiles}

At the end of August 1991 (experiment 1), two trenches $1.5 \mathrm{~m}$ deep were dug on the irrigated plots for the N2 treatment of each species. On each inner side of these trenches perpendicularly to the sowing rows of the crops, the presence or absence of root impacts inside grids of $2 \times 2 \mathrm{~cm}$ was determined according to the method described by Tardieu and Manichon (1986). The root density was estimated for each $10-\mathrm{cm}$ soil layer as the proportion of grid units having at least one root impact.

\section{Statistical methods}

The results of the experiments underwent two different types of analyses. Firstly, each measurement at each observation date was submitted to a univariate analysis of variance in order to provide tests of the differences between treatments together with confidence intervals at specific stages. The model was the following:

$$
Y_{i j k}=\mu+\alpha_{i} / \beta_{j}+(\alpha \beta)_{i j}+\gamma_{k}+(\beta \gamma)_{j k}+\varepsilon_{i j k}
$$

where $Y_{i j k}$ is the quantitative observation depending on block $i$, irrigation regime $j$, and treatment $k . \mu$ is the grand mean, $\alpha$ is the effect of blocks, $\beta$ is the irrigation vs non-irrigation effect, and $\gamma$ is the treatment effect. According to the experiment, parameter $\gamma$ identifies either the genotype-nitrogen effect, or the genotype-row spacing effect. In addition, $(\alpha \beta)$ stands for the block by irrigation interaction (the error stratum for the test of the effect of irrigation) and ( $\beta \gamma$ ) stands for the irrigation by treatment interaction. $\varepsilon$ is the general error term of the model.

In a second step, non-linear analyses were performed on the different varieties by treatment combinations, in order to provide tests of the differences in growth pattern between treatments (varieties, irrigation regimes and row spacing). We have used the standard logistic model. Let $Y_{i}$ be the response (leaf area index, biomass accumulation) recorded at stage growth $D_{i}$. The model used can be written:

$$
Y_{i}=\theta_{0}+\theta_{1} /\left[1+\mathrm{e}^{-\theta_{2}\left(D_{i}-\theta_{3}\right)}\right]+\varepsilon_{i}
$$

The parameters $\theta_{0}, \theta_{1}, \theta_{2}$ and $\theta_{3}$ have the following statistical significations: $\theta_{0}$ is the value of the response at the origin of the curve; $\theta_{1}$ is the range of the response; $\theta_{2}$ is the maximum slope of the response, estimated at the inflexion point $\theta_{3}$. A separate curve is fitted for each treatment combination. Likelihood-ratio tests are computed in order to compare sub-models generated by equality constraints between the regression parameters. The calculations were made with the S-Plus package software (Becker et al, 1988; Bouvier and Huet, 1993).

\section{RESULTS}

\section{Potential growth in dry matter}

The potential growth of Furio maize and DK18 sorghum was estimated in experiment 1 (1991) on the treatment non limited in water and nitrogen. Figure 1 shows the accumulation kinetics of the aerial biomass for the two crops. The difference between the two species in accumulated biomass became significant on the 70th day after sowing, and the maximum biomass at the end of the growth period proved significantly different. In addition, the non-linear regression analysis showed that all parameters except the maximum biomass could be similar for the two species $(P=$ 0.045 ). Figure 2 shows that the leaf area index of Furio developed earlier than that of DK18. This is confirmed by the estimation of the parameters
Fig 1. Dry matter accumulation kinetics of maize cv Furio (ם) and sorghum cv DK18 $(\Delta)$ in irrigated conditions and with an input of $200 \mathrm{kgN}^{-h a^{-1}}$. (-: LSD $\left.P=0.05\right)$.

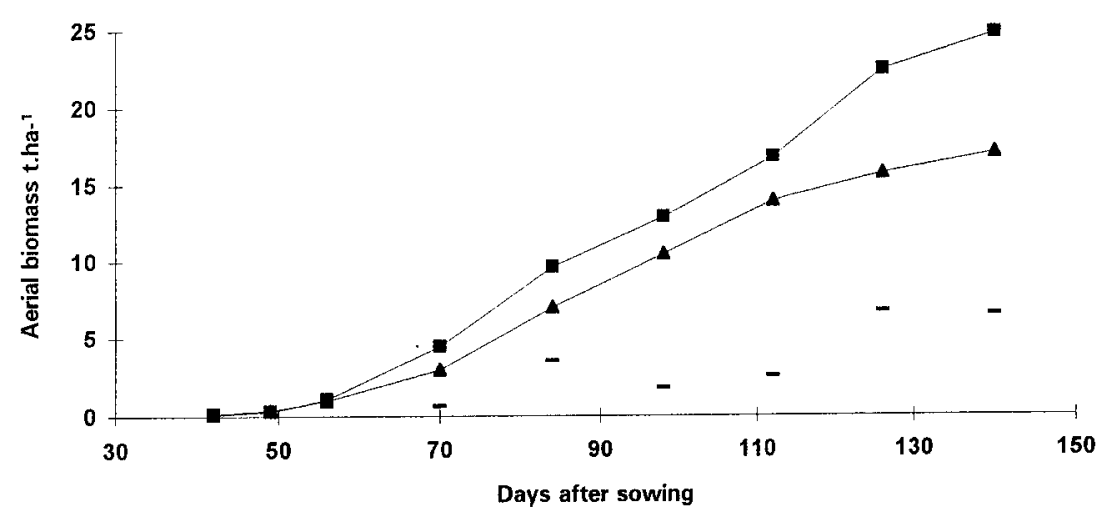


which showed a lower abcissa of the inflexion point for the maize variety. The consequence is that Furio reached an $L A I$ value of 1 ten days earlier than DK18. However, the LAI of maize reached a maximum value of 4.8 on the 97 th day after sowing whereas the LAl of sorghum continued to increase until the 111th day and reached the value of 5.5. The regressions between the accumulated dry matter (DM) and the quantity of visible radiation intercepted $\left(\mathrm{PAR}_{\mathrm{i}}\right)$ by each of the crops were calculated for the period 0-111 days after sowing before the beginning of leaf senescence (fig 3). The slopes of these two regressions represent an estimate of the conversion efficiency of the PAR intercepted (RUE) by each of the two crops. These values, $3.31{\mathrm{~g} . \mathrm{MJ}^{-1} \text { for }}^{-1}$ maize and $3.18 \mathrm{~g}^{\mathrm{M}} \mathrm{MJ}^{-1}$ for sorghum, were not statistically different. We could therefore conclude that the differences in production between the maize and sorghum crops were essentially the consequence of a difference in the development of the leaf area and not a result of the difference in use efficiency of the energy intercepted. The existence of a non-zero intercept was probably due to a slight overestimation of the LAI for the early stages of growth.

\section{Water consumption}

Dynamics of water consumption of N2 treatment of sorghum and maize during experiment 1 are presented in figure 4. The faster LAl expansion of maize with irrigation leads to a higher water consumption than for sorghum ( $610 \mathrm{~mm}$ vs $460 \mathrm{~mm}$ ). In non-irrigated treatment, water consumption of sorghum appears slightly higher than that of maize $(350 \mathrm{~mm}$ vs $330 \mathrm{~mm})$. Thus, in 1991, water consumption of sorghum was relatively less reduced by drought than that of maize. During experiment 2 (data not shown), maize had also a higher water consumption than sorghum (410 vs $350 \mathrm{~mm}$ ) in irrigated treatment, while this difference was lower in non-irrigated treatments ( 370 vs $350 \mathrm{~mm}$ ). Thus, in 1992, drought slightly reduced water consumption in maize while water consumption of sorghum was not affected. The row spacing does not significantly affect the water consumption of the two crops, either in irrigated or in non-irrigated conditions.

Figure 5 shows the soil water consumption of each soil layer under the two crops in experiment 1 between 26 June and 21 August. This last date
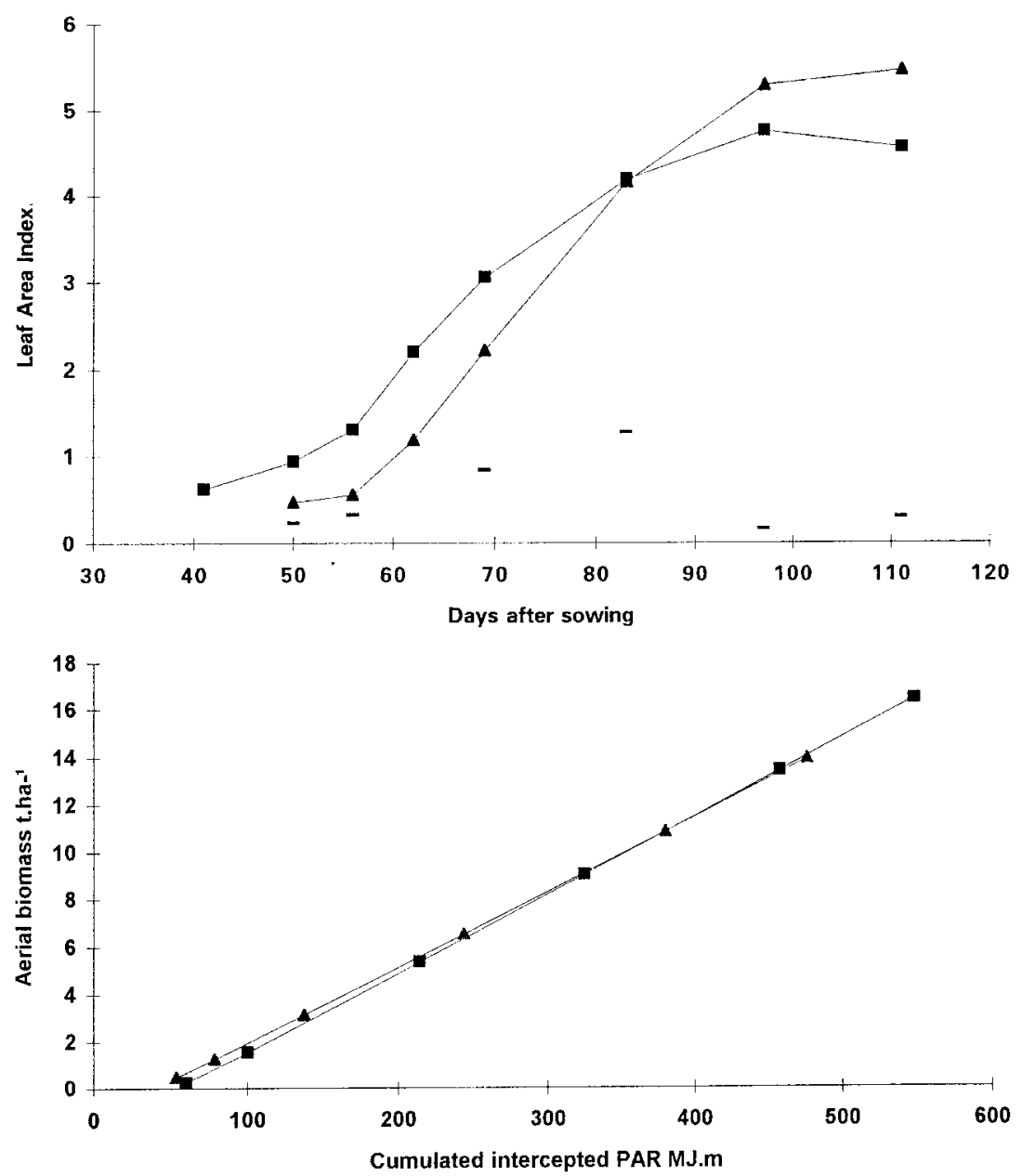

Fig 2. Time-course of the leaf area index of maize cv Furio (a) and sorghum cV DK18 $(\mathbf{A})$ in irrigated conditions and with an input of $200 \mathrm{kgN} \cdot \mathrm{ha}^{-1}$. (-: LSD $P=$ 0.05).
Fig 3. Relationship between the accumulation of aerial biomass (ADM) and the quantity of intercepted PAR $\left(\right.$ PAR $\left._{\mathrm{i}}\right)$. maize cv Furio $(\mathbf{D}):$ ADM $=3.31$ $( \pm 0.14) \mathrm{PAR}_{\mathrm{i}}-1.77( \pm 0.69) r^{2}=0.991$; sorghum CV DK18 (A): ADM $=3.18$ $( \pm 0.08) \mathrm{PAR}_{\mathrm{i}}-1.25( \pm 0.33) r^{2}=0.997$. 
corresponds to the maximum soil drought. We can observe that the profiles of soil water consumption under the two crops were relatively similar. Sorghum does not exhibit higher soil water extraction in the deeper soil layer and only a slightly higher capacity for water extraction than maize at each soil layer from soil surface until $1 \mathrm{~m}$ depth. This profile confirms the observations on root density profiles (fig 6): a higher root density of sorghum at every soil layer from soil surface to $1 \mathrm{~m}$ depth (corresponding to the loam horizon), and the absence of roots in the red clay horizon, except through very localized cracks and worms tunnels.

\section{Growth in limiting conditions and nitrogen uptake dynamics}

\section{Experiment 1}

Figures $7 \mathrm{a}$ and $7 \mathrm{~b}$ make it possible, for each crop, to compare growth in conditions where water and (or) nitrogen limited potential growth.

Fig 4. Dynamics of water consumption of maize cv Furio $(\square)$ and sorghum cv DK18 (A), in irrigated (closed symbols) and non-irrigated (open symbols) conditions during experiment I (1991).

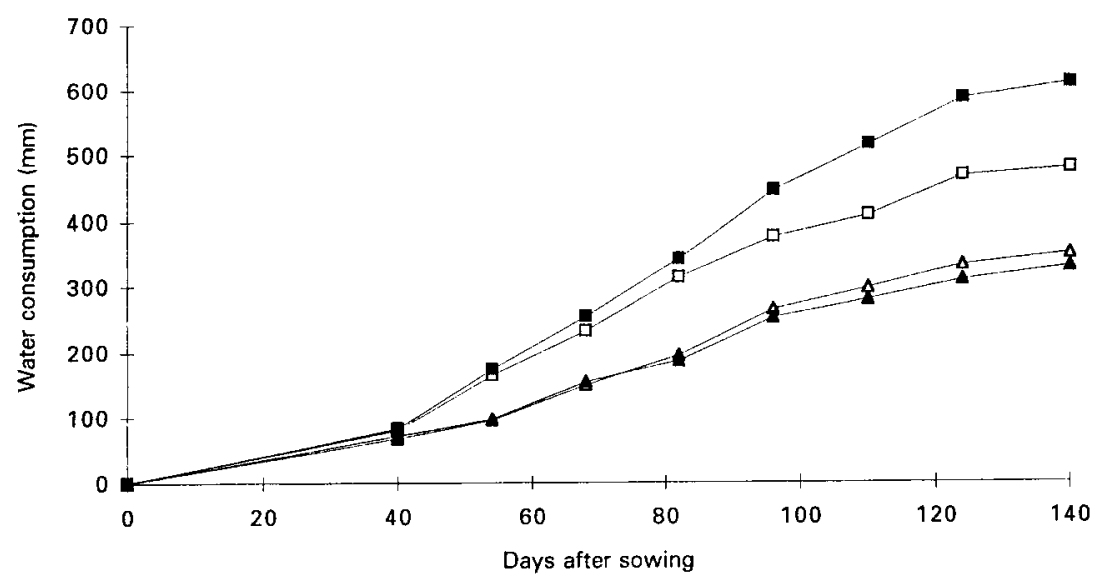

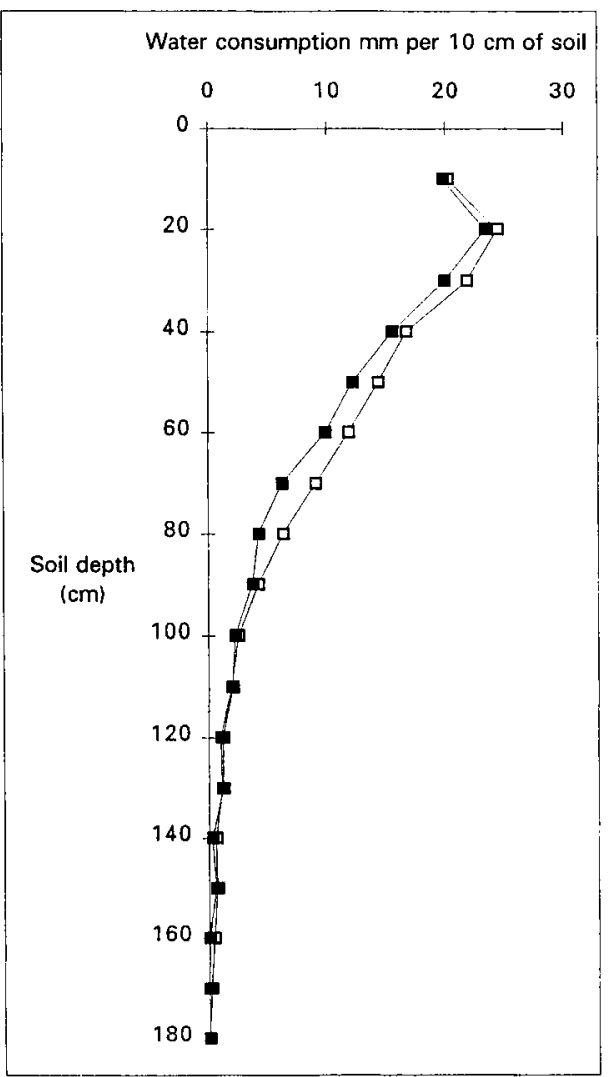

Fig 5. Water consumption in $10 \mathrm{~cm}$ soil layers of sorghum ( $\square$ ) and maize $(\square)$ in non-irrigated conditions between 26 June and 21 August 1991 (experiment 1).

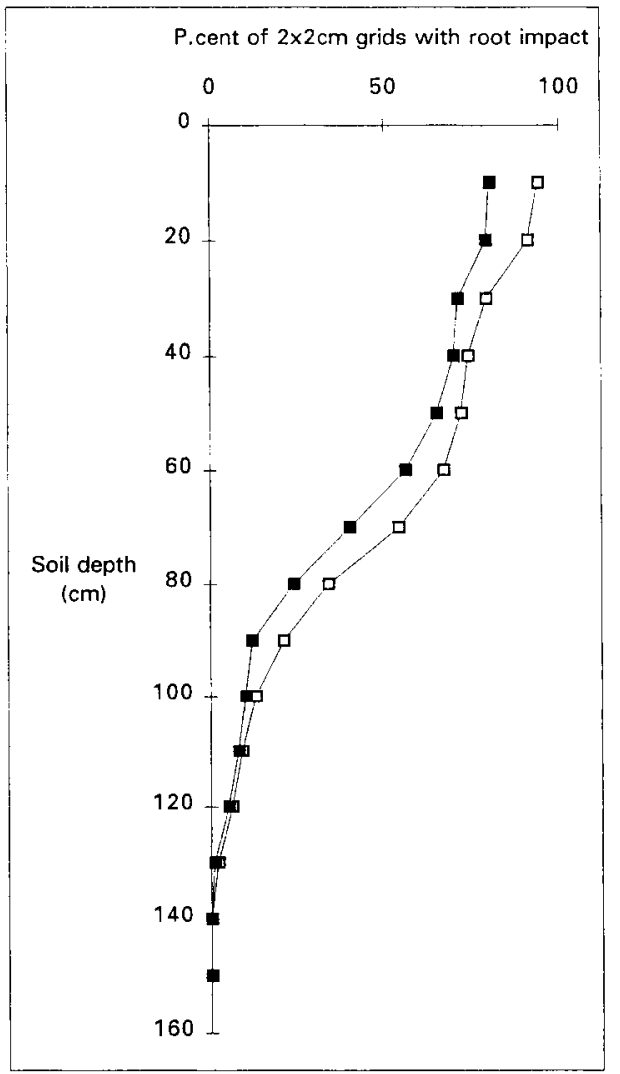

Fig 6. Root density profiles as estimated by frequency of root impact presence in $2 \times 2 \mathrm{~cm}$ grids for sorghum ( () and maize (ロ) in non-irrigated conditions. 
For Furio (fig 7a), the effect of nitrogen was not significant in dry conditions. In irrigated conditions, a difference in biomass became significant at the end of the growing period (after the 98th day). Water deficit led to a loss of biomass of $63 \%$ : 9.02 t.ha-1 $^{-1}$ vs 24.75 t.ha $^{-1}$ in irrigated conditions. The statistical test revealed a significant nitrogen by water supply interaction, since the effect of nitrogen was only significant when irrigation was provided.

For DK18 sorghum, no effect of nitrogen appeared, either in irrigated or in dry conditions. Accumulated biomass without irrigation was 13.27 tha ${ }^{-1}$, which was a deviation of 3.40 t.ha- $^{-1}$ compared to the potential biomass, corresponding to a $20 \%$ decrease. The analysis of variance confirmed the absence of an effect of nitrogen on sorghum whatever the irrigation regime.
The difference in accumulated biomass between maize and sorghum in irrigated conditions appears to be more or less proportional to the difference observed in water consumption. Therefore, the water-use efficiency of the two crops are similar: $41 \mathrm{~kg} \cdot \mathrm{mm}^{-1}$ for Furio and $37 \mathrm{~kg} . \mathrm{mm}^{-1}$ for DK18. In non-irrigated conditions, a large difference in accumulated biomass between the two crops was obtained with similar water consumptions, leading to lower water-use efficiency for maize $\left(27 \mathrm{~kg} \cdot \mathrm{mm}^{-1}\right)$ than for sorghum (38 kg. $\mathrm{mm}^{-1}$ ).

Figures $8 \mathrm{a}$ and $8 \mathrm{~b}$ make it possible to compare the nitrogen uptake dynamics of the different treatments and to situate them with respect to the general model determining the 'critical' nitrogen uptake of $\mathrm{C}_{4}$ plants. For Furio maize, it was confirmed that the irrigated $\mathrm{N} 1$ treatment had a a

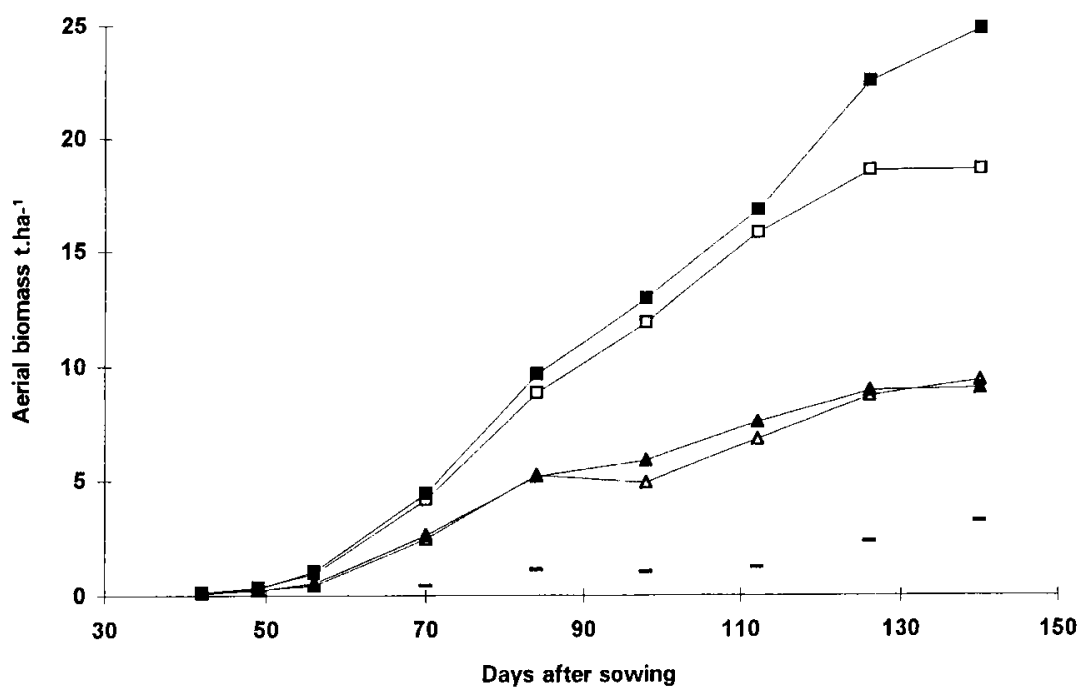

b

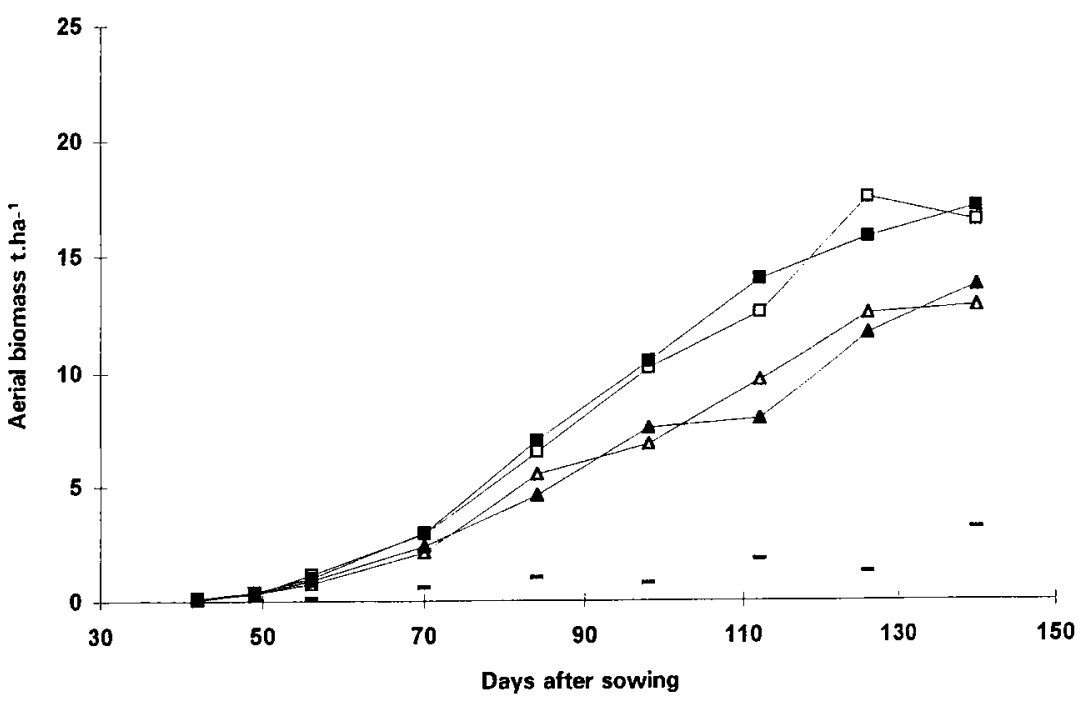

Fig 7. Dry matter accumulation kinetics of maize cv Furio (a) and sorghum cv DK18 (b) for different growth conditions. Experiment 1 (1991). (-: LSD $P=0.05)$.

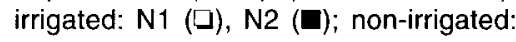
N1 ( $\Delta)$, N2 (A). 
limited nitrogen uptake from the fifth measurement point, which corresponded to the 84th day after sowing. After this date, the values of the NNI were significantly less than 1 (table I). This date corresponded to the beginning of a difference with the N2 treatments, visible on figure $7 a$, which confirmed the validity of the diagnosis concerning nitrogen nutrition based on the NNI value. The N2 treatment provided the crop with a non-limiting nitrogen uptake up to the end of the growth period, the NNI values remaining greater than 1 (table I). The two non-irrigated plots, whatever the nitrogen applied, showed the same intensity of nitrogen nutrition deficit which showed that the drought had greatly limited the availability of the nitrogen supplied. The nitrogen nutrition level tended to be restored at the end of growth (fig $8 \mathrm{a}$ and table I) which coincided with a rainy period, allowing a better availability of soil $\mathrm{N}$ for plants.

For DK18 sorghum, figure $8 \mathrm{~b}$ shows that the irrigated $\mathrm{N} 1$ treatment was not limiting in nitrogen at any time. The NNI remained constantly much higher than 1 (table 1). For the N2 treatment,

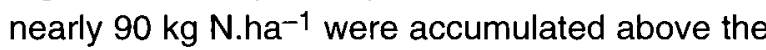
'critical' requirements of the crop. In dry conditions, as for maize, a clear decrease in nitrogen uptake was observed compared to irrigated conditions. However for the two nitrogen supply levels, the NNI remained close to 1 (table I) which indicated that the drought did not cause any nitrogen nutrition deficit in the sorghum, in contrast to the observations for maize.

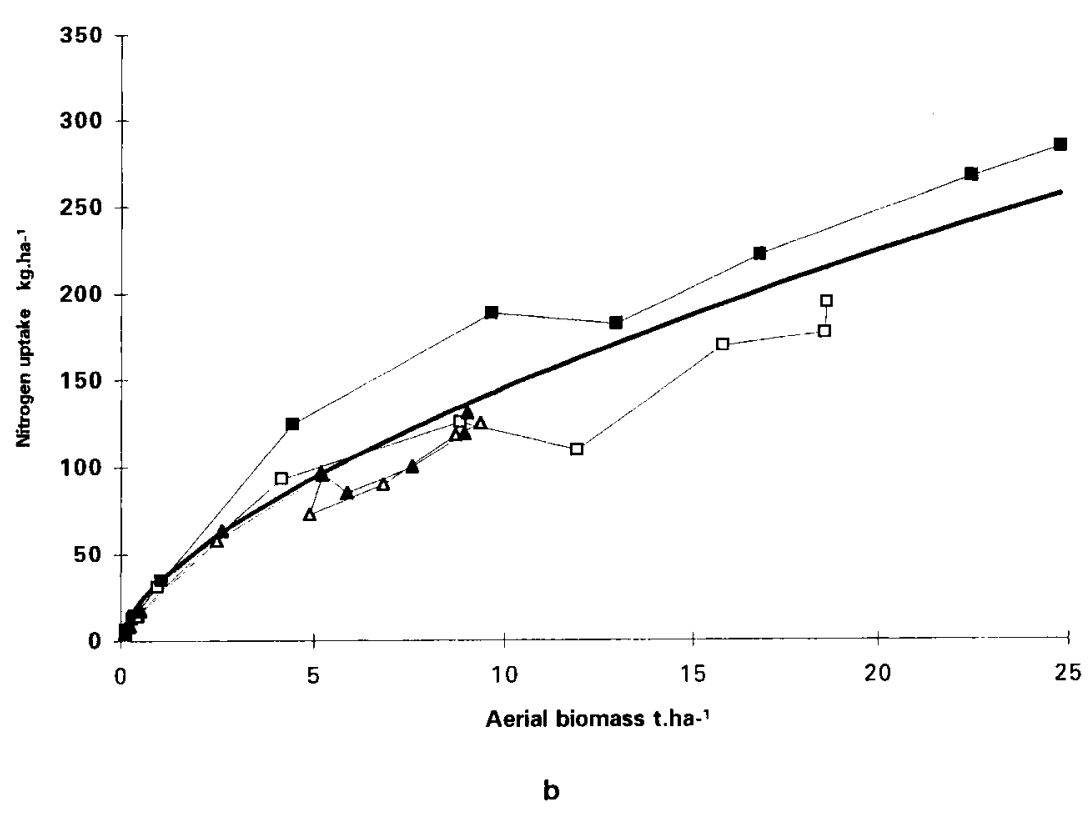

Fig 8. Relationship between nitrogen uptake dynamics (kg Nha- ${ }^{-1}$ ) and the accumulation dynamics of aerial biomas (ADM tha ${ }^{-1}$ ) for maize cv Furio (a) and sorghum CV DK18 (b) experiment 1 (1991); irrigated: $N 1$ (D),

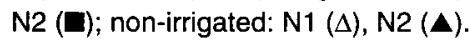

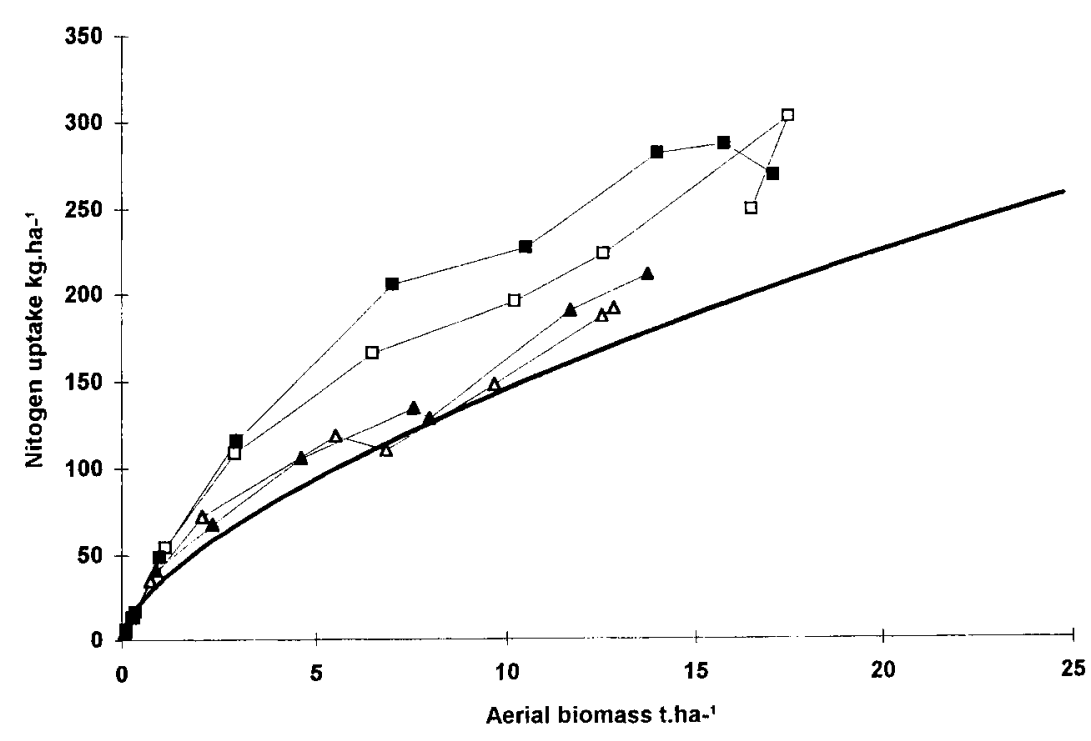


Table I. Evolution of the NNI for maize cv Furio and sorghum cv DK18 experiment 1.

\begin{tabular}{|c|c|c|c|c|c|c|c|c|c|}
\hline \multirow{2}{*}{$\begin{array}{l}\text { Day after } \\
\text { sowing }\end{array}$} & \multicolumn{4}{|c|}{ Furio } & \multicolumn{3}{|c|}{$D K 18$} & \multirow{2}{*}{$\operatorname{Sec} N 2$} & \multirow[t]{2}{*}{$\angle S D$} \\
\hline & $\operatorname{Irr} N 1$ & $\operatorname{Irr} N 2$ & $\operatorname{Sec} N 1$ & $\operatorname{Sec} N 2$ & $\operatorname{Irr} N 1$ & $\operatorname{Irr} N 2$ & $\operatorname{Sec} N 1$ & & \\
\hline 42 & 1.32 & 1.35 & 1.13 & 1.13 & 1.35 & 1.36 & 1.43 & 1.37 & 0.078 \\
\hline 49 & 1.21 & 1.25 & 1.05 & 1.09 & 1.37 & 1.34 & 1.31 & 1.29 & 0.047 \\
\hline 56 & 0.95 & 0.99 & 0.94 & 0.93 & 1.48 & 1.46 & 1.39 & 1.37 & 0.037 \\
\hline 70 & 1.11 & 1.43 & 0.96 & 1.01 & 1.63 & 1.72 & 1.34 & 1.46 & 0.130 \\
\hline 84 & 0.94 & 1.33 & 0.99 & 1.01 & 1.50 & 1.77 & 1.19 & 1.19 & 0.071 \\
\hline 98 & 0.68 & 1.07 & 0.79 & 0.82 & 1.33 & 1.52 & 0.97 & 1.10 & 0.075 \\
\hline 112 & 0.88 & 1.10 & 0.79 & 0.82 & 1.33 & 1.57 & 1.04 & 1.02 & 0.055 \\
\hline 126 & 0.83 & 1.11 & 0.89 & 0.88 & 1.46 & 1.48 & 1.12 & 1.19 & 0.085 \\
\hline 140 & 0.91 & 1.11 & 0.90 & 0.96 & 1.25 & 1.32 & 1.13 & 1.19 & 0.164 \\
\hline
\end{tabular}

a

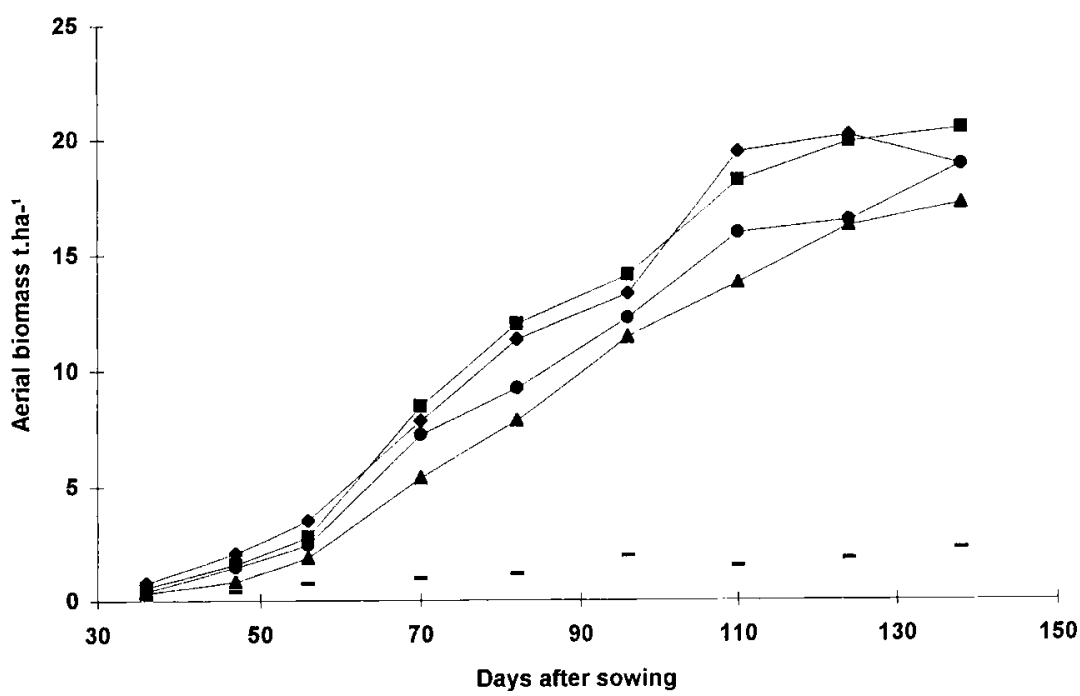

b

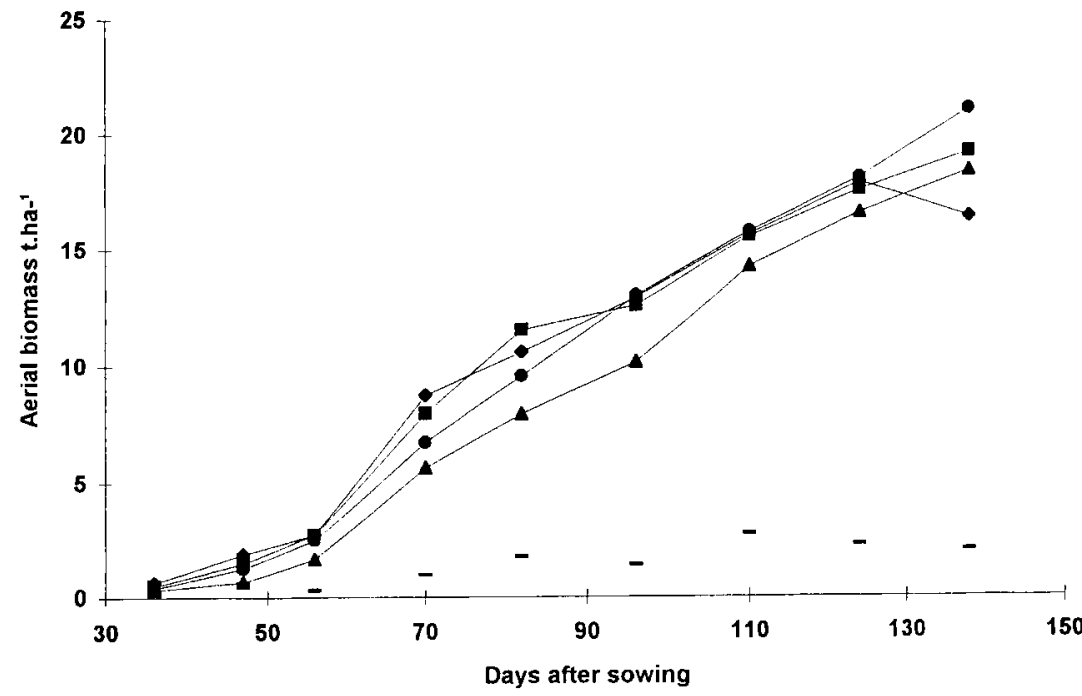

Fig 9. Dry matter accumulation of the two maize genotypes cv Furio and cv Yamba and the two sorghum genotypes cv DK18 and cv Argence in irrigated conditions (a) and in dry conditions (b). Experiment 2 (1992). (-: LSD $P=0.05$ ) maize: cv Furio (ロ); cv Yamba (*); sorghum: cv DK18 (A); cv Argence (-). 
The variance analysis confirmed that at each sampling date, except for the first one, the NNI of sorghum was significantly higher than that of maize under all conditions $(0.01<P<0.001 \%)$.

\section{Experiment 2}

Figures $9 \mathrm{a}$ and $9 \mathrm{~b}$ make it possible to compare of the growth in dry matter of the two varieties of maize, Furio and Yamba, and the two varieties of sorghum, DK18 and Argence, grown at their normal row spacings of 75 and $50 \mathrm{~cm}$ respectively. The analysis of variance did not show any significant differences between the varieties on species for the rate of growth. The assumption underlying the constraint of equality of the regression slopes of all the treatment combinations could not be rejected $(P=0.808)$, even though Argence seemed to have a slightly higher growth rate than DK18 in non-limiting conditions. In addition, the study of several sets of equality constraints on the parameters associated with either irrigated or non-irrigated conditions showed that no differences within species in any parameters could be assumed under irrigation, whereas only the slope of the regression models revealed non-significant differences within species in the absence of irrigation. In this latter case, the only significant differences concerned the maximum biomass production which was simultaneously affected by genotypes and conditions, as a consequence of different ways of lowering the accumulation of dry matter at the end of the growth period between genotypes. Beyond day 82, there was a clear change in the growth of the two maize varieties and the differences in biomass production with the two sorghum varieties lessened and disap-

a

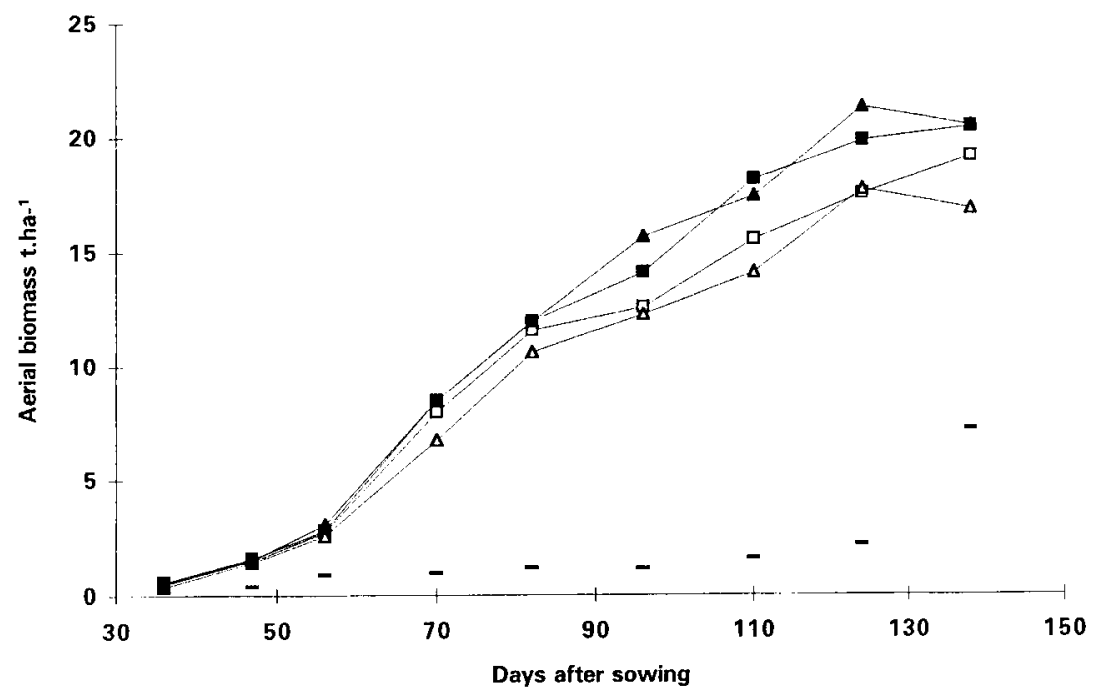

b

Fig 10. Dry matter yield of maize cv Furio (a) and sorghum cv DK18 (b) depending on row spacing $75 \mathrm{~cm}(\square, \square)$ or $50 \mathrm{~cm}(\Delta, \Delta)$, in irrigated conditions $(\boldsymbol{\square}, \boldsymbol{\Delta})$ and in dry conditions $(\square, \Delta)$. Experiment 2 (1992). (-: LSD $P=0.05)$.

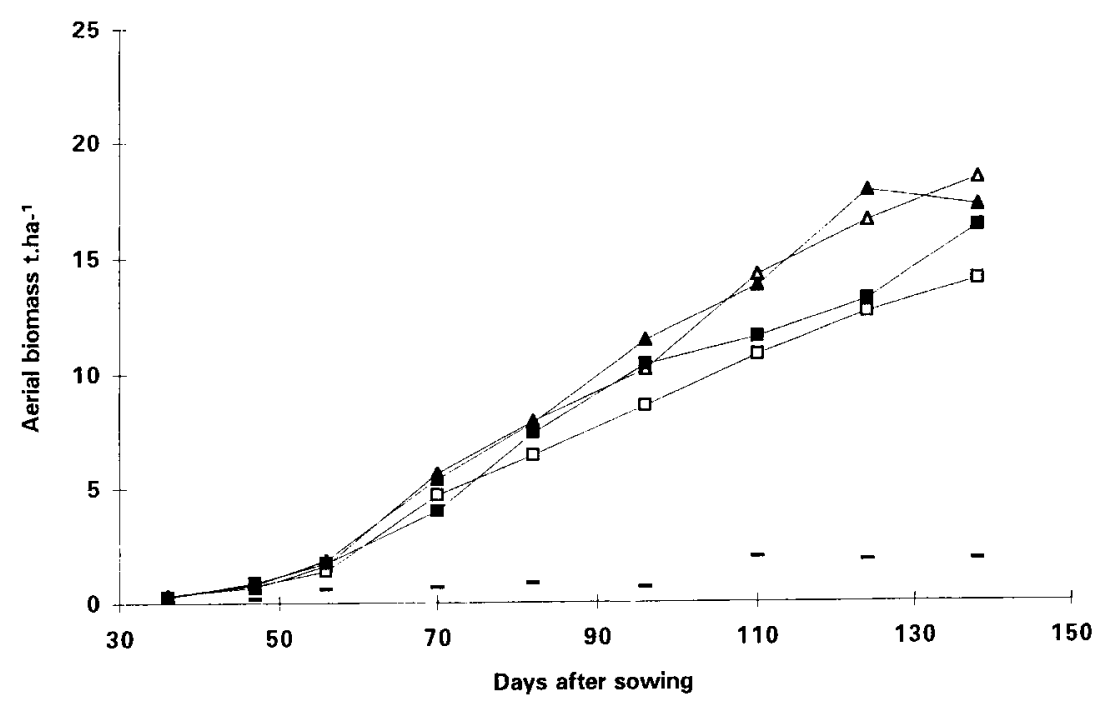


peared. Examining growth simultaneously under dry irrigated conditions pointed to the existence of a 'species $x$ water supply' interaction, the effect of the drought having caused a reduction of 2.0-2.5 tha th $^{-1}$ in the biomass produced by the two maize varieties and having practically no effect on the two sorghum varieties. The observed effect of drought on biomass accumulation of maize is convergent with the difference observed in water consumption of this species between irrigated and non-irrigated conditions, and in the same way the absence of drought effect on biomass of sorghum is attested by the absence of any difference in water consumption between the two water regimes.

Figures $10 \mathrm{a}$ and $10 \mathrm{~b}$ make it possible to analyse the effect of row spacing for the two varieties, Furio and DK18. Row spacing differently affected Furio and DK18; no significant difference was noticed between regression models with 50 and $75-\mathrm{cm}$ row spacings on maize, whereas the equality constraints must have been rejected with DK18, since the maximum biomass accumulation strongly differed between treatments (the difference in final biomass accumulation reached about 2 t.ha $^{-1}$ ). The small size of the sorghum variety (a dwarf genotype) could not compensate for the decrease in soil cover despite the tillering potential of this species. The behaviour of Furio depends on the water regime and this genotype accumulates significantly more biomass at the end of the growth period under irrigated compared to non-irrigated conditions. Our results and tests confirm the absence of visible effects of drought on the growth curves of sorghum.

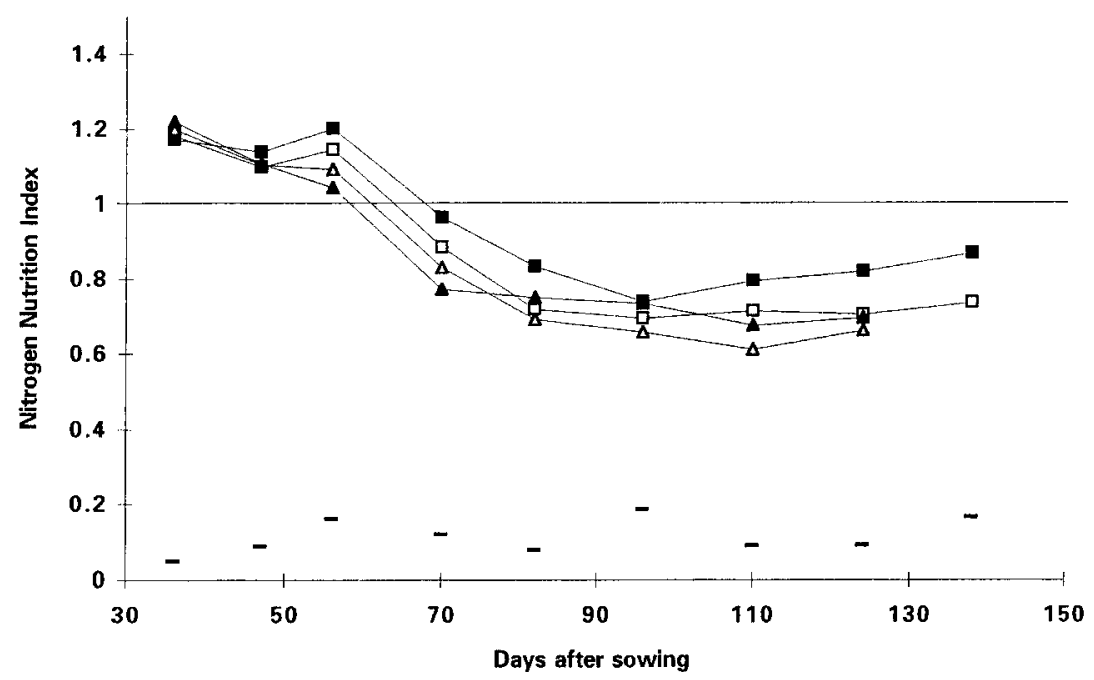

b

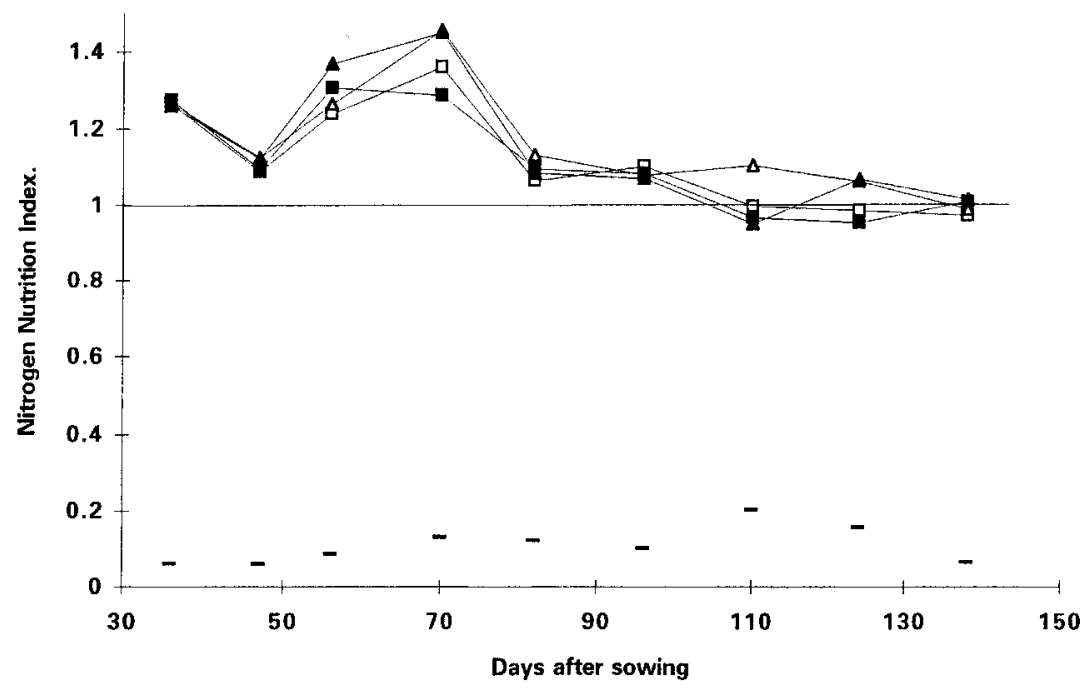

Fig 11. Evolution of the NNI during the growth of maize cv Furio (a) and sorghum cv DK18 for the two row spacings of 75 and $50 \mathrm{~cm}$, in irrigated and dry conditions (same symbols as fig 10). 
The evolution of the NNI values for Furio maize and DK18 sorghum, and for the two row spacings, are represented in figures $11 \mathrm{a}$ and $11 \mathrm{~b}$. For maize, the nitrogen nutrition remained optimum until the 56th day after sowing. Subsequently, all the treatments underwent a major deficit in nitrogen nutrition with NNI values dropping below 0.8 . For sorghum, the nitrogen nutrition remained optimum up until the 96 th day after sowing. Then a slight nitrogen nutrition deficit occurred, but with NNI values not dropping below 0.8 . This reflected a major difference between the nitrogen uptake capacities of the two genotypes. This difference seemed to be independent of row spacings and water supply conditions, although in maize a better level of nitrogen nutrition was observed with row spacings of $75 \mathrm{~cm}$. The difference observed between Furio and DK18 was confirmed perfectly with the two other genotypes, Yamba and Argence (figs $12 \mathrm{c}$ and $12 \mathrm{~d}$ ). Perfect agreement was also observed between the estimates of the NI values for the different genotypes, which tended to prove that the variations in this index over time should reflect variations in the real $\mathrm{N}$ availability for crops, thus reinforcing the 'diagnosis' value of this index.

\section{DISCUSSION}

\section{Potential growth}

In the absence of nitrogen and water limitations, the potential yield of maize was higher than that of sorghum. This difference was essentially due to the rapid development of the LAI of maize,

a

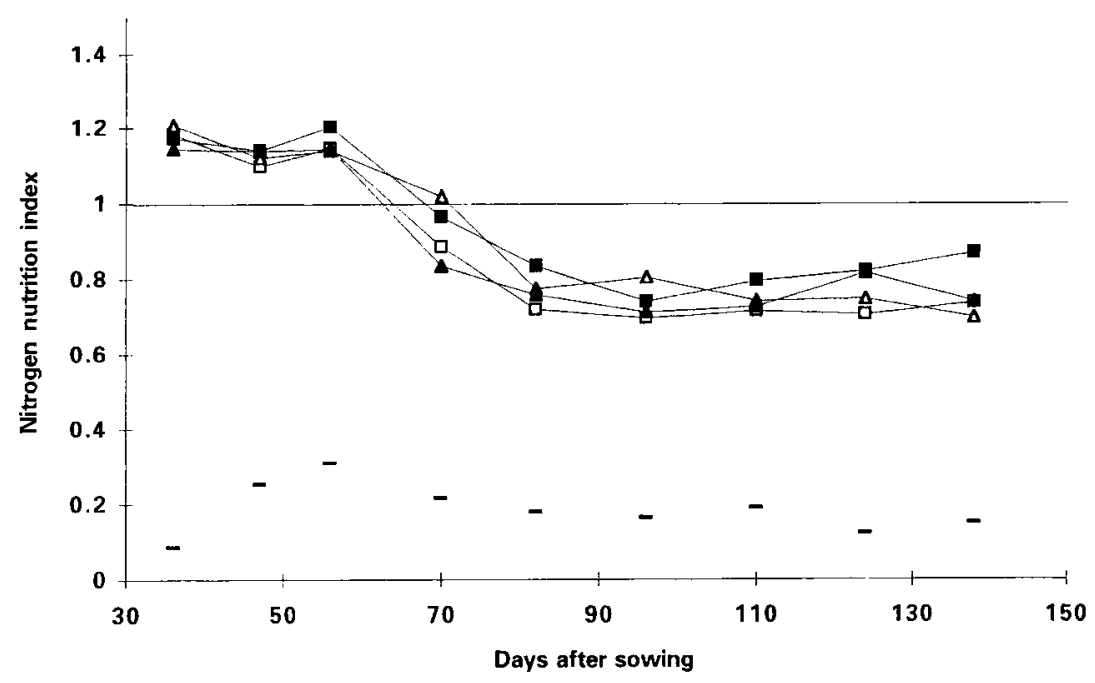

b

Fig 12. Comparison of the evolution of the $\mathrm{NNI}$ in dry conditions (open symbols) and in irrigated conditions (solid symbols) for: a) the two maize varieties: cv Furio $(\boldsymbol{\square}, \square)$; cv Yamba $(\boldsymbol{\Delta}, \Delta)$; b) the two sorghum varieties: cv DK18 (ם, $\square)$; cv Argence $(\mathbf{\Lambda}, \Delta)$.

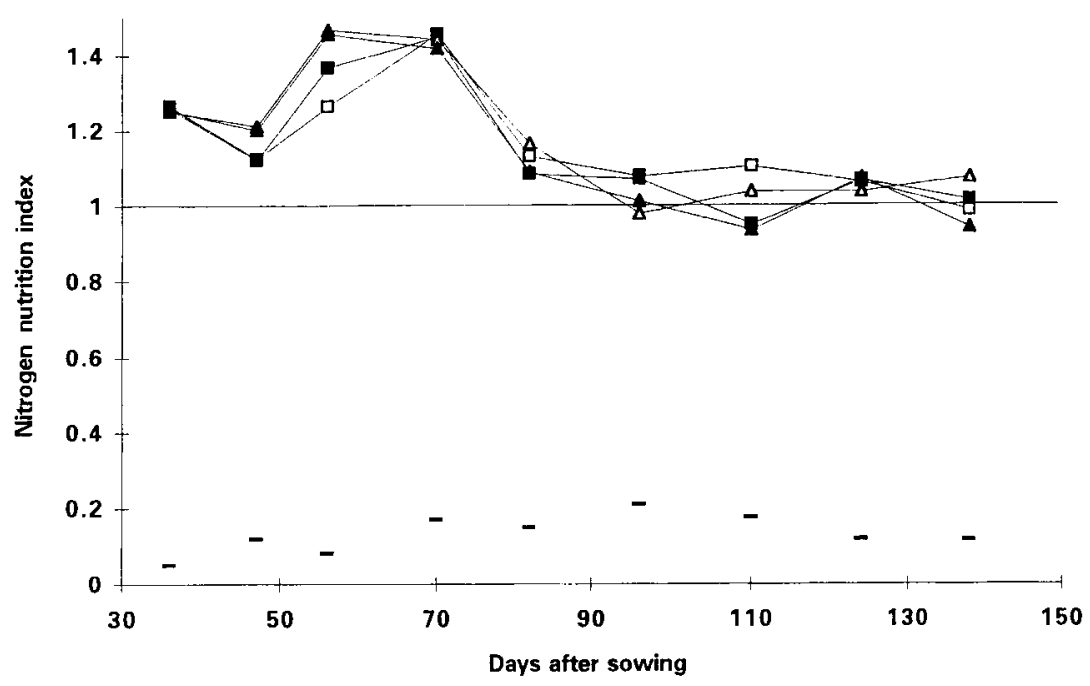


enabling a greater interception of the incident PAR. The efficiency of conversion of PAR into aerial biomass (RUE) was identical for both species. The values obtained for DK18 and Furio were in agreement with those reported for $\mathrm{C}_{4}$ plants (Kiniry et al, 1989; Gosse et al, 1986; Sivakumar and Virmani, 1984). The lack of any significant difference in the RUE of the two species was however in contradiction with the results of Muchow and Davis (1988) which showed a higher value for maize than for sorghum. However, these authors pointed out that the difference observed in the RUE between sorghum and maize disappeared when the calculations were carried out on the basis of total biomass rather than just above-ground biomass, because of the higher root/shoot growth of sorghum. The absence of quantified data on the root biomass of these two species in our experiments prevented us from coming to any definite conclusions on this point.

\section{Uptake dynamics and nitrogen use efficiency}

For all growth conditions tested, the nitrogen uptake of sorghum was always higher than that of maize when the comparisons were made at the same stage of biomass produced in order to eliminate the differences caused by the growth dynamics of each species. This difference in 'intrinsic' nitrogen uptake capacities could be seen in the maintenance of a higher NNI for sorghum than for maize with an equivalent nitrogen supply level. Row spacing did not appear to be a determining factor in the crop nitrogen uptake capacity as the differences observed seemed to be attributable to the species and were observed for each of the genotypes tested. These results may however appear contradictory to those reported by Muchow and Davis (1988) who indicated no difference in nitrogen uptake between maize and sorghum crops for a large range of nitrogen supplies, but their comparisons were carried out at equivalent growth duration and not at equivalent biomass.

Analysing nitrogen uptakes at the same date on figure 8 demonstrates that for a very high nitrogen supply level (irrigated N2 treatment in experiment 1), sorghum and maize took up equivalent quantities of nitrogen at the end of growth: approximately $290 \mathrm{~kg} \cdot \mathrm{ha}^{-1}$. Since sorghum growth potential is lower than that of maize, the former therefore accumulated an excess of approximately $90 \mathrm{~kg} \cdot \mathrm{ha}^{-1}$ of $\mathrm{N}$ com- pared to its critical requirements. With a nitrogen supply limited to $30 \mathrm{~kg} \cdot \mathrm{ha}^{-1}$, sorghum took up identical quantities of nitrogen at the end of growth when supplied with $200 \mathrm{~kg} \cdot \mathrm{ha}^{-1}$, but with delayed kinetics, whereas maize only managed to capture a limited quantity of nitrogen: 190 $\mathrm{kg} . \mathrm{ha}^{-1}$, which only enabled it to have NNI values between 0.7 and 0.8 at the end of growth. This difference between maize and sorghum in their nitrogen-uptake capacities from soil with limited nitrogen availability is confirmed in figure 11 . For all the sorghum plots, the NNI remained higher than or equal to 1 up to the 82nd day after sowing. At this date, the average nitrogen uptake in all treatments was $140 \mathrm{~kg} \cdot \mathrm{ha}^{-1}$. For all the maize plots, the nitrogen nutrition remained non-limiting only until the 56th day after sowing, the nitrogen uptake being on average only $70 \mathrm{~kg} \cdot \mathrm{ha}^{-1}$. Therefore with a nitrogen supply limited to 50 $\mathrm{kg} \cdot \mathrm{ha}^{-1}$, sorghum was able to extract twice as much nitrogen from the soil as maize before its nitrogen nutrition became limiting.

If we accept that the curve connecting critical $\mathrm{N}$ content and crop biomass is identical for the two species, this implies that, at the same biomass, the marginal $\mathrm{N}$ requirements $(\mathrm{dN} / \mathrm{dDM})$ are identical for both species. Thus higher growth rate of maize leads to higher rate of $\mathrm{N}$ uptake than for sorghum. The maximum rate of $\mathrm{N}$ uptake by a crop depends on (i) nitrate concentration in soil solution, (ii) root density, and (iii) specific root absorption capacity. Therefore, for similar root density and root properties, a higher crop demand in $\mathrm{N}$ requires a higher soil nitrate concentration to be fed, ie, a higher $\mathrm{N}$ flux from soil to root surfaces. This simple reason could explain why maize, exhibiting higher $\mathrm{N}$ uptake rate requirement $\left(\mathrm{kgN} \cdot \mathrm{ha}^{-1}\right.$.day-1) can use a smaller part of the available soil $\mathrm{N}$ before $\mathrm{N}$ deficiency occurs, in comparison with sorghum which, with lower $\mathrm{N}$ uptake rate requirement, can use a greater proportion of the available soil $\mathrm{N}$ without any $\mathrm{N}$ restriction. Thus we may postulate that the higher the growth rate (ie, the higher the $\mathrm{N}$ uptake rate requirement) the lower is the proportion of soil $\mathrm{NO}_{3}{ }^{-}$which can be absorbed by a crop without $\mathrm{N}$ nutrition restriction.

Drought reduced the nitrogen uptake of the two species. A part of this decrease was explained by the effect of drought on growth and another part by a direct effect on nitrogen availability as shown in figure 8 . Therefore, in non-irrigated conditions, sorghum managed to maintain its nitrogen uptake at a non-limiting level, while maize underwent a nitrogen-nutrition deficit which was added to the direct effect of drought 
on its growth. The $\mathrm{N}$ effect induced by drought can explain the lower water-use efficiency of maize in non-irrigated conditions in 1991, while the water-use efficiency of sorghum was not affected. This difference between maize and sorghum has been previously observed by Marty and Puech (1971), but no clear explanation has yet been proposed. This difference can be illustrated by calculation of the ratio between $\mathrm{N}$ uptake and water consumption for the two crops under irrigated and non-irrigated situations during experiment 1 . This ratio changed from 0.7 $\mathrm{kgN} \cdot \mathrm{mm}^{-1}$ under irrigated conditions to 1.2 $\mathrm{kgN} . \mathrm{mm}^{-1}$ under dry conditions for sorghum, and from 0.5 to $0.7 \mathrm{kgN} . \mathrm{mm}^{-1}$ for maize for the same conditions. These figures indicate that for both conditions the $\mathrm{N}$ uptake capacity of sorghum per unit of water consumed is higher than that of maize. Such an observation implies that, compared to maize, sorghum crop should lead to a reduced nitrate concentration in soil solution after harvest and therefore to a reduction of the risk of $\mathrm{NO}_{3}$ - leaching the following winter. Drought increases the $\mathrm{N} /$ water ratio for the two species, but this increase is more accentuated for sorghum that for maize indicating that $\mathrm{N}$ nutrition is less affected by soil-drying conditions for sorghum than for maize. The absence of strong differences in root density and soil water extraction profiles between the two species indicates that the difference in $\mathrm{N}$ uptake capacity between the two species cannot be attributable to differences in root distribution. Only the specific $\mathrm{N}$ uptake capacity of elementary root fraction should explain the observed differences in overall crop $\mathrm{N}$ uptake capacity. The origin of this difference: specific $\mathrm{NO}_{3}-$ transport capacity, and (or) micro-structure of the root-soil interface remains unknown.

In conclusion, the observation that sorghum had a greater intrinsic aptitude to satisfy its nitrogen requirements, with a better uptake capacity of $\mathrm{N}$ from the soil, gives this species an undeniable agronomic advantage over maize, owing to its greater adaptation to growing conditions limiting in water and nitrogen. However, the results obtained did not make it possible to identify the origin of the differences observed between the two species. Examining the relative aerial/underground growth kinetics of the two species could provide a grid for analysing the balance between the nitrogen supply characterized by the uptake capacities of the root system and the nitrogen demand which is determined mainly by the dynamics of the leaf area development. The hypothesis of more fundamental differences linked to the nitrogen dynamics in the rhizosphere of the two species, or to the mechanisms for absorbing $\mathrm{NO}_{3}-$ by the roots, may also be put forward but would require specific studies. The method of analysis which we used enabled the nitrogen requirements of each crop to be taken into account and a comparison to be made of their intrinsic aptitudes to satisfy their nitrogen demand in soil with a given nitrogen availability. In this way, what is commonly called the 'nitrogen supply' of a soil, namely the quantity of nitrogen taken up by a crop in the absence of input by fertilization, appeared to be as much a characteristic of the plant species cultivated as of the 'soil-climate' context. It therefore appeared important to determine very accurately the pertinent morphological and physiological parameters of the crop which in the end determine the real nitrogen availability of the soil.

\section{REFERENCES}

Becker RA, Chambers JM, Wilks AR (1988) The new $S$ language; a programming environment for data analysis and graphics. Wadsworth \& Brooks - Cole Advanced Books \& Software, Pacific Grove, CA, USA

Biscoe PV, Gallagher JN (1977) Weather, dry-matter production and yield. In: Environmental Effects on Crop Physiology, Proc Symp Long Ashton (JJ Landsberg, CV Cutting, eds), 75-100

Bonhomme B, Ruget F, Derieux M, Vincourt P (1982) Relations entre production de matière sèche aérienne et énergie interceptée chez différents génotypes de maïs. C R Acad Sc Paris, série III 294, 393-398

Bouvier A, Huet S (1993) Reference Manual of the nls2 Library. INRA, Laboratoire de Biométrie, Jouyen-Josas, France

Goss G, Varlet-Grancher C, Bonhomme R, Chartier M, Allirand JM, Lemaire G (1986) Production maximale de matière sèche et rayonnement solaire intercepté par un couvert végétal. agronomie 6, 47-56

Greenwood DJ, Lemaire G, Gosse G, Cruz P, Draycott A, Neeteson JJ (1990) Decline in percentage $N$ of $\mathrm{C}_{3}$ and $\mathrm{C}_{4}$ crops with increasing plant mass. Ann Bot 66, 425-436

Jones CA, Kiniry JR (1986) CERES-MAIZE, a simulation model of maize growth and development. Texas A \& M University Press, College Station, USA, $194 p$

Kiniry JR, Jones CA, O'Toole JC, Blanchet R, Cabelguenne M, Spanel DA (1989) Radiation-use efficiency in biomass accumulation prior to grain filling to five grain crop species. Field Crops Research $20,51-64$ 
Lemaire G, Salette J (1984) Relation entre dynamique de croissance et dynamique de prélèvement d'azote pour un peuplement de graminées fourragères. 1. Études de l'effet du milieu. agronomie 4, 423-430

Lemaire G, Denoix A (1987) Croissance estivale en matière sèche de peuplements de fétuque élevée (Festuca arundinacea Schreb) et de dactyle (Dactylis glomerata L) dans l'ouest de la France. II. Interaction entre les niveaux d'alimentation hydrique et de nutrition azotée. agronomie 7, 381-389

Lemaire G, Gastal F, Salette J (1989) Analysis of the effect of $\mathrm{N}$ nutrition on dry matter yield of a sward by reference to potential yield and optimum $\mathrm{N}$ content. Proc XVIth Int Grassland Congress, Nice, France, 179-180

Lemaire G, Chartier M (1992) Relationships between growth and dynamics of nitrogen uptake for individual sorghum plants growing at different plant densities. Proc 2nd Congress of European Society of Agronomy, Warwick University, 98-99

Marty JR, Puech J (1971) Efficience de l'eau en production fourragère. CR Acad Agric 57, 938-949

Monteith JL (1977) Climate and the efficiency of crop production in Britain. Phil Trans $R$ Soc, London, $B$ $281,277-294$
Muchow RC, Davis R (1988) Effect of nitrogen supply on the comparative productivity of maize and sorghum in a semi-arid tropical environment. II. Radiation interception and biomass accumulation. Field Crops Research 18, 17-30

Plenet D (1985) Fonctionnement des cultures de maïs sous contrainte azotée ; détermination et application d'un indice de nutrition. PhD Thesis, Institut national polytechnique de Lorraine, Université de Nancy, $104 \mathrm{p}$

Ruget F, Bonhomme R, Varlet-Grancher C (1990) Analyse de la fonction de photosynthèse dans CERES-MAIZE. Proc Colloque Physiologie et Production du Maïs, Pau, France (INRA, ed), 445453

Sivakumar MVK, Virmani SM (1984) Crop productivity in relation to interception of photosynthetic active radiation. Agric Forest Meteor 31, 131-141

Tardieu F, Manichon H (1986) Caractérisation en tant que capteur d'eau de l'enracinement du maïs en parcelle cultivée. 2. Une méthode d'étude de la répartition verticale et horizontale des racines. agronomie 6, 415-425

Varlet-Grancher C, Lemaire G, Cruz P, Bonhomme R, Gastal F, Gosse G (1989) Maximal aerial dry matter production by forage sorghum. Proc 5th Congress on Biomass for Energy and Industry. Lisbone 